This is a postprint version of the following published document:

Nicolas, J., Miguel, V. S., Mantovani, G. \& Haddleton,

D. M. (2008). Fluorescently labeled protein-polymer bioconjugates using protein-derived macroinitiators from living radical polymerization. ACS Symposium Series, 977, pp. 78-94.

"This document is the unedited Author's version of a Submitted Work that was subsequently accepted for publication in ACS Symposium Series, copyright (C) 2008 American Chemical Society after peer review.

To access the final edited and published work see http://pubs.acs.org/doi/abs/10.1021/bk-2008-0977.ch006?src $=$ recsys or see DOI: 10.1021/bk-2008-0977.ch006." 


\title{
Fluorescently Labeled Protein-Polymer Bioconjugates Using Protein-Derived Macroinitiators from Living Radical Polymerization
}

\author{
Julien Nicolas ${ }^{1}$, Veronica San Miguel $^{2}$, Giuseppe Mantovani ${ }^{1}$, \\ and David M. Haddleton ${ }^{1, *}$ \\ ${ }^{1}$ Department of Chemistry, University of Warwick, \\ Coventry CV4 7AL, United Kingdom \\ ${ }^{2}$ Instituto de Ciencia y Tecnologia de Polimeros, CSIC, Juan de la Cierva 3, \\ 28006 Madrid, Spain
}

Bovine Serum Albumin (BSA) and lysozyme have been chemically transformed into macroinitiators for the synthesis of fluorescent bioconjugates by living radical polymerization. A new fluorescent monomer based on rhodamine $B$ has been synthesized and incorporated into the polymer backbone of the bioconjugate by copolymerization. This provides a new strategy for the synthesis of fluorescent bioconjugates with improved traceability in biological environments, during biomedical assays. 


\section{Introduction}

Protein-polymer conjugates is an emerging research area, representing an established way to new and more efficient therapeutics for application in biotechnology and medicine. Bioconjugation often refers to the linking of a (macro)molecule to (poly)peptides/proteins in order to form new chemical entities which are able to retain the bioefficacy and features of the peptide whilst enjoying enhancements from the polymer. The most significant example is the covalent modification of proteins with poly(ethylene glycol) (PEG), pegylation $(1,2,3,4)$. The resulting conjugates exhibited multiple benefits including improved biodistributions and pharmacokinetics, improved resistance to proteolysis, reduced immunogenicity/antigenicity, longer plasma half-life and improved solubility when compared to non-pegylated counterparts (5). The emergence of living radical polymerization (LRP) has provided an efficient tool to design the nature and characteristics of the polymer conjugated to the protein. Transition-metal-mediated living radical polymerization (also called atom transfer radical polymerization, ATRP) $(6,7)$, nitroxide-mediated polymerization (NMRP) (8) and reversible transfer as reversible addition fragmentation transfer (RAFT) (9) allow various tailor-made polymers featuring unique properties in terms of molecular weight, molar mass distribution and chain-end functionality to be synthesized. This provides a powerful tool for protein/peptide biology. Protein and peptides currently constitute approximately $10 \%$ of the market for molecular medicines (total $>400$ bn USD) which is growing year on year. As such; technological developments can have a real and immediate impact in this area.

We have recently reported studies involving the "grafting to" strategy for synthesizing bioconjugates by copper-mediated living radical polymerization, the conventional route for pegylation. $\alpha$-Functional well-defined polymers were used as alternative pegylation agents and reacted with residual amines (lysine and $N$-terminal $\alpha$-amino residues) and thiols (cysteine residues) present at the surface of proteins $(10,11,12)$. In contrast, the "grafting from" synthetic route, which consists of transforming a protein into a macroinitiator for subsequent polymerization, has not been as widely investigated $(13,14)$.

In this present work, we present a strategy for synthesizing fluorescent bioconjugates by LRP starting from previously modified proteins as macroinitiators. Materials containing fluorescent tags are extremely useful due to their increased traceability in biological systems during biomedical assays as the location of the material can be observed and hence its effectiveness may be determined. In addition, they can be observed using fluorescence microscopy and especially laser scanning confocal microscopy. 


\section{Experimental Part}

\section{Materials}

Albumin, from bovine serum (BSA, molecular weight $\sim 66 \mathrm{kDa}, \mathrm{V}$ fraction), lysozyme (molecular weight $\sim 14.3 \mathrm{kDa}$ ), poly(ethylene glycol) methyl ether methacrylate (PEGMA 475 , average $M_{\mathrm{n}}=475$ g.mol ${ }^{-1}$, Aldrich), 2(dimethylamino)ethyl methacrylate (DMAEMA, Aldrich, 99\%) and methacryloyl chloride (Aldrich, 97\%) were used as received without further purification. Copper(l) bromide was purified by stirring over glacial acetic acid and followed by rinsing with ethanol and diethyl ether. Anhydrous dimethyl sulfoxide (DMSO, Aldrich, 99\%), triethylamine (TEA, Fischer, 99\%, stored over potassium hydroxide pellets), dichloromethane (DCM, Fischer, >99\%), acetonitrile (BDH, 99.9\%, HPLC grade) and trifluoroacetic acid (TFA, Aldrich, $99 \%$ ) were used as received. $N$-(Ethyl)-2-pyridylmethanimine was prepared as described earlier (15) and stored under dinitrogen atmosphere at $4{ }^{\circ} \mathrm{C}$. Hostasol methacrylate fluorescent monomer, maleimide and $\mathrm{N}$-succinimidyl 2-bromo-2methylpropionate initiators were prepared as described elsewhere $(16,11,12)$.

\section{Analytical techniques}

${ }^{1} \mathrm{H}$ NMR and ${ }^{13} \mathrm{C}$ NMR spectra were recorded on a Bruker DPX 400 spectrometer using deuterated chloroform $\left(\mathrm{CDCl}_{3}\right.$, Aldrich) as a solvent. Fluorescence spectroscopy was performed on a Perkin Elmer LS 50B spectrofluorometer with $1 \mathrm{~cm}$ quartz cuvette at $200 \mathrm{~nm} \cdot \mathrm{min}^{-1}$ scan speed, $2.5 \mathrm{~nm}$ excitation and emission slit widths, ambient temperature in phosphate buffer (10 $\mathrm{mM}, \mathrm{pH}=7.1$ ). U.V.-Visible spectroscopy analysis was performed on a Jasco V-550 spectrophotometer with $1 \mathrm{~cm}$ quartz cuvette, $0.5 \mathrm{~nm}$ data pitch, 200 nm.min ${ }^{-1}$ scan speed, ambient temperature in phosphate buffer $(10 \mathrm{mM}, \mathrm{pH}=$ 7.1). Circular Dichroism (CD) analysis was performed on a Jasco J715 spectropolarimeter with $0.1 \mathrm{~cm}$ quartz cuvette, $0.2 \mathrm{~nm}$ data pitch, $100 \mathrm{~nm} . \mathrm{min}^{-1}$ scan speed, 8 accumulations, ambient temperature in phosphate buffer $(10 \mathrm{mM}$, $\mathrm{pH}=7.1$ ) for a concentration of $0.1 \mathrm{mg} \cdot \mathrm{mL}^{-1}$. Percentages of $\alpha$-helices and $\beta$ sheets were determined by applying the protein $C D$ structure-fitting program, CDSSTR (18).

The RP-HPLC system was fitted with a Phenomenex column (Jupiter, $\mathrm{C}_{18}$, $4.6 \times 250 \mathrm{~mm}, 5 \mu \mathrm{m}, 300 \AA$ ) and a U.V. detector (Gilson, UV-VIS-155) at 280 $\mathrm{nm}$ under a flow rate of $1 \mathrm{~mL} \cdot \mathrm{min}^{-1}$. The separation was performed under a gradient between mobile phase A (acetonitrile/water, 90/10, v/v and $0.05 \%$ TFA) and mobile phase B (100\% acetonitrile, $0.04 \%$ TFA). The gzadient 
involved several linear steps: 0 min $90 \%$ A, $27 \mathrm{~min} 40 \% \mathrm{~A}, 35 \mathrm{~min} 40 \% \mathrm{~A}, 37$ $\min 90 \% \mathrm{~A}$, and $45 \mathrm{~min} 90 \% \mathrm{~A}$. SEC-FL-HPLC system was carried out on two BioSep-SEC-S3000 columns with fluorescence detection (Hitachi, L-7480) continuously measuring the relative intensity of the mobile phase. The system was eluted with 0.1 vol.\% TFA in water and acetonitrile $(69 / 31, \mathrm{v} / \mathrm{v})$ at a flow rate of $0.5 \mathrm{~mL} \cdot \mathrm{min}^{-1}$.

SDS-PAGE was conducted using a stacking polyacrylamide gel of $5 \%$ cross-linking, a resolving polyacrylamide gel ( $8 \%$ cross-linking for BSA conjugates; $12 \%$ cross-linking for lysozyme conjugate) and a running buffer consisting of $25 \mathrm{mM}$ of TRIS base, $250 \mathrm{mM}$ of glycerol, $0.1 \%$ of SDS at pH 8.7, bromophenol blue with addition of DTT for reducing conditions (17).

\section{Synthesis of rhodamine B methacrylate monomer}

Both TEA (1.44 g, $14.3 \mathrm{mmol})$ and methacryloyl chloride $(0.97 \mathrm{~g}, 10.7$ mmol) were sequentially added at $0{ }^{\circ} \mathrm{C}$ to a solution of rhodamine $\mathrm{B}$ alcohol (19) $(5.93 \mathrm{~g}, 9.80 \mathrm{mmol})$ in DCM $(100 \mathrm{~mL})$, After $1 \mathrm{~h}$, the temperature was raised to ambient temperature and the mixture stirred for a further $12 \mathrm{~h}$. The volatiles were then removed under reduced pressure and the residue purified by a preeluted flash chromatography $\left(\mathrm{SiO}_{2}\right)$ using methanol/triethylamine $(95 / 5)$, to give rhodamine $\mathrm{B}$ methacrylate monomer as purple glassy solid in $72 \%$ yield.

${ }^{1} \mathrm{H}$ NMR $\left(400.03 \mathrm{MHz}, \mathrm{CDCl}_{3}, 298 \mathrm{~K}\right): \delta=1.20(\mathrm{t}, J=7.0 \mathrm{~Hz}, 12 \mathrm{H}), 1.67-$ $1.76(\mathrm{q}, J=6.8 \mathrm{~Hz}, 2 \mathrm{H}), 1.78(\mathrm{~s}, 3 \mathrm{H}), 2.24(\mathrm{br} \mathrm{s}, 4 \mathrm{H}), 2.31(\mathrm{t}, J=7.2 \mathrm{~Hz}, 2 \mathrm{H})$, $3.30($ br s, $4 \mathrm{H}), 3.50-3.55(\mathrm{q}, J=7.3 \mathrm{~Hz}, 8 \mathrm{H}), 4.02(\mathrm{t}, J=6.4 \mathrm{~Hz}, 2 \mathrm{H}), 5.38-$ $5.45(\mathrm{~m}, 1 \mathrm{H}), 5.91-5.96(\mathrm{~m}, 1 \mathrm{H}), 6.63-6.68(\mathrm{~d}, J=2.5 \mathrm{~Hz}, 2 \mathrm{H}), 6.80-6.91$ (dd, $J=2.3,9.5 \mathrm{~Hz}, 2 \mathrm{H}), 7.07-7.15(\mathrm{~d}, J=9.5 \mathrm{~Hz}, 2 \mathrm{H}), 7.19-7.25(\mathrm{~m}, 1 \mathrm{H}), 7.41-$ $7.49(\mathrm{~m}, 1 \mathrm{H}), 7.51-7.61(\mathrm{~m}, 2 \mathrm{H}) .{ }^{13} \mathrm{C} \mathrm{NMR}\left(100.59 \mathrm{MHz}, \mathrm{CDCl}_{3}, 298 \mathrm{~K}\right): \delta=$ $12.50,18.12,25.51,41.34,46.01,47.17,52.19,52.88,54.48,62.52,96.11$, $113.52,114.32,125.40,127.51,129.77,129.99,130.06,130.46,131.91$, $135.17,136.02,155.44,155.70,157.54,167.12,167.22$. IR (solid, ATR cell): $v$ $\left(\mathrm{cm}^{-1}\right) 3070\left(=\mathrm{CH}_{2}\right), 1709(\mathrm{C}=\mathrm{O}$ ester carbonyl $), 1635(\mathrm{C}=\mathrm{O}$ amide $), 1582(\mathrm{C}=\mathrm{C}$ aromatic), 1460 ( $\mathrm{C}=\mathrm{C}$ aromatic), 1250 (C-O ester), 1169 (C-O ester), 1070 (C-O ether). High resolution MS-ES calcd. for $\mathrm{C}_{39} \mathrm{H}_{49} \mathrm{~N}_{4} \mathrm{O}_{4}(\mathrm{M}+)$ : 637.3754 ; found: 637.3760 .

\section{Preparation of protein-macroinitiators}

\section{BSA-macroinitiator}

BSA (34 mg, $0.52 \mu \mathrm{mol}$ ) was dissolved in $4.6 \mathrm{~mL}$ of $100 \mathrm{mM}$ phosphate buffer $(\mathrm{pH}=7.0)$. A solution of $15 \mathrm{mg}$ of maleimide initiator $(51.7 \mu \mathrm{mol}) \underset{4}{0.2}$ 
$\mathrm{mL}$ of DMSO was slowly added. The mixture was gently stirred for $12 \mathrm{~h}$ at ambient temperature and the solid residue was removed by centrifugation. The supernatant was diluted with deionized water and dialyzed with a 12,000-14,000 molecular weight cut-off (MWCO) membrane against deionized water for several days. The solution was then lyophilized to isolate the BSAmacroinitiator.

\section{Lysozyme-macroinitiator}

$N$-Hydroxysuccinimide-2-bromo-2-methylpropionate $(37 \mathrm{mg}, 140 \mu \mathrm{mol})$ in $400 \mu \mathrm{L}$ of DMSO was added to lysozyme $(100 \mathrm{mg}, 7.0 \mu \mathrm{mol})$ dissolved in 20 $\mathrm{mL}$ of phosphate buffer $(100 \mathrm{mM}, \mathrm{pH}=7.0)$. To this, $50 \mu \mathrm{L}$ of a TEA solution of $2.26 \mathrm{mM}$, prepared by dissolving $50 \mu \mathrm{L}$ of TEA in $0.16 \mathrm{~mL}$ of phosphate buffer $(100 \mathrm{mM}, \mathrm{pH}=7.0)$, was added. The mixture was incubated at ambient temperature during $48 \mathrm{~h}$ under gentle stirring. The suspension was diluted with water and the solid residue was removed by centrifugation. The supernatant was dialyzed using a 6,000-8,000 MWCO membrane against deionized water for several days. The solvent was removed by lyophilization to isolate the lysozymemacroinitiator.

\section{Preparation of fluorescent bioconjugates}

\section{BSA-poly(PEGMA ${ }_{475}$-co-rhodamine B methacrylate)}

BSA-macroinitiator (100 mg, $1.5 \mu \mathrm{mol})$, PEGMA $_{475}(0.11 \mathrm{~g}, 0.38 \mathrm{mmol})$ and $\mathrm{Cu}(\mathrm{I}) \mathrm{Br}$ ( $32 \mathrm{mg}, 0.23 \mathrm{mmol})$ were placed in a Schlenk tube and were dissolved in $23.8 \mathrm{~mL}$ of deionized water. $200 \mu \mathrm{L}$ of a stock solution of rhodamine $\mathrm{B}$ monomer $(3.8 \mu \mathrm{mol})$, previously prepared by dissolving $25 \mathrm{mg}$ of the rhodamine $\mathrm{B}$ monomer in $2 \mathrm{~mL}$ of deionized water, was added. The solution was then deoxygenated by three freeze-pump-thaw cycles. Subsequently three vacuum-nitrogen cycles were applied and the Schlenk was placed in an oil bath at $25^{\circ} \mathrm{C}$. $N$-(Ethyl)-2-pyridylmethanimide $(59 \mu \mathrm{L}, 0.48 \mathrm{mmol})$ was added and the reaction mixture immediately turned dark brown/red. After $48 \mathrm{~h}$ under nitrogen atmosphere, the reaction medium was diluted with deionized water and bubbled with air overnight. The solid residue was removed by centrifugation and the supernatant was dialyzed using a 12,000-14,000 MWCO membrane against deionized water. The solution was lyophilized and the BSA-poly(PEGMA $\mathrm{P}_{45}-\mathrm{CO}-$ rhodamine B methacrylate) conjugate was obtained as a purple solid. 
BSA-macroinitiator $(75 \mathrm{mg}, 1.1 \mu \mathrm{mol}), \operatorname{PEGMA}_{475}(85 \mathrm{mg}, 0.28 \mathrm{mmol})$ and $\mathrm{Cu}(\mathrm{I}) \mathrm{Br}$ (24 mg, $0.17 \mathrm{mmol}$ ) were placed in a Schlenk tube and dissolved in DMSO $(17.8 \mathrm{~mL})$. The hostasol monomer $(1.3 \mathrm{mg}, 2.8 \mu \mathrm{mol})$ was added and the mixture deoxygenated by three freeze-pump-thaw cycles. The Schlenk tube was placed in an oil bath at $25^{\circ} \mathrm{C}$ and $N$-(ethyl)-2-pyridylmethanimide $(44 \mu \mathrm{L}, 0.36$ mmol) as a polymerization initiator (the reaction medium turned a dark brown/orange color). The mixture was stirred under inert atmosphere for $48 \mathrm{~h}$ prior to dilution with DMSO and bubbled with air overnight. The suspension was centrifuged and the supernatant was then diluted with deionized water. The solid residue was removed by centrifugation and the supernatant was dialyzed using a 12,000-14,000 MWCO membrane against deionized water. The solvent was removed by lyophilization in order to isolate a yellow solid.

\section{BSA-poly(DMAEMA-co-rhodamine B methacrylate)}

BSA macroinitiator $(100 \mathrm{mg}, 1.5 \mu \mathrm{mol})$ was dissolved in $23.6 \mathrm{~mL}$ of degassed water. A solution of DMAEMA $(200 \mu \mathrm{L}, 0.38 \mathrm{mmol})$ was added (prepared by dissolving $630 \mu \mathrm{L}$ of DMAEMA in $2 \mathrm{~mL}$ of deionized water and adding some drops of $\mathrm{HCl}$ until $\mathrm{pH}$ 6.6). To this, $200 \mu \mathrm{L}$ of a rhodamine B monomer solution $(3.8 \mu \mathrm{mol})$, obtained by dissolving $25 \mathrm{mg}$ of the fluorescent monomer in $2 \mathrm{~mL}$ of deionized water, was added. The mixture was deoxygenated with three freeze-pump-thaw cycles. $\mathrm{Cu}(\mathrm{I}) \mathrm{Br}(32 \mathrm{mg}, 0.23 \mathrm{mmol})$ was subsequently added to the frozen mixture and three vacuum-nitrogen cycles were applied. Then, the Schlenk tube was placed in an oil bath at $25^{\circ} \mathrm{C}$ under a nitrogen atmosphere. $N$-(Ethyl)-2-pyridylmethanimide $(59 \mu \mathrm{L}, 0.48 \mathrm{mmol}$ ), reaction mixture turned a dark brown/red color. After 17 hours, the polymerization medium was diluted with deionized water and bubbled with air overnight. The solid residue was removed by centrifugation and the supernatant dialyzed using a 12,000-14,000 MWCO membrane against deionized water for several days. The solution was lyophilized to give the conjugate as a purple solid.

\section{Lysozyme-poly(PEGMA ${ }_{475}$-co-rhodamine B methacrylate)}

Lysozyme-macroinitiator $(18 \mathrm{mg}, 1.1 \mu \mathrm{mol})$, PEGMA 475 ( $83 \mathrm{mg}, 0.28$ mmol) and $\mathrm{Cu}(\mathrm{I}) \mathrm{Br}(24 \mathrm{mg}, 0.17 \mathrm{mmol})$ were dissolved in $15 \mathrm{~mL}$ of deionized water. Rhodamine B monomer solution, $150 \mu \mathrm{L}(2.8 \mu \mathrm{mol}), 19 \mathrm{mg}$ of the fluorescent monomer in $2 \mathrm{~mL}$ of deionized water, was added. The solution was 
subsequently deoxygenated by three freeze-pump-thaw cycles and placed in an oil bath at $25{ }^{\circ} \mathrm{C}$. $N$-(Ethyl)-2-pyridylmethanimide $(44 \mu \mathrm{L}, 0.35 \mathrm{mmol}$ ) was added, the reaction mixture immediately turning dark brown/red. The mixture was stirred for $\mathbf{4 8}$ hours under nitrogen. The reaction medium was then diluted with deionized water and bubbled with air overnight. The mixture was centrifuged to remove the solid residue and the supernatant dialyzed using a 12,000-14,000 MWCO membrane against deionized water. The solution was then lyophilized to isolate the desired conjugate as a purple solid.

\section{Results and Discussion}

Synthesis of the rhodamine B methacrylate monomer as a fluorescent probe

Fluorescent bioconjugates were prepared by in situ incorporation of the fluorescent probe during the synthesis of the polymer by copolymerization of fluorescent monomers with poly(ethylene glycol) methyl ether methacrylate (PEGMA ${ }_{475}$ ) or with dimethyl aminoethyl methacrylate (DMAEMA). Both the hostasol methacrylate monomer $(16)$ and novel fluorescent methacrylate monomer derived from rhodamine B (Scheme 1) were employed.
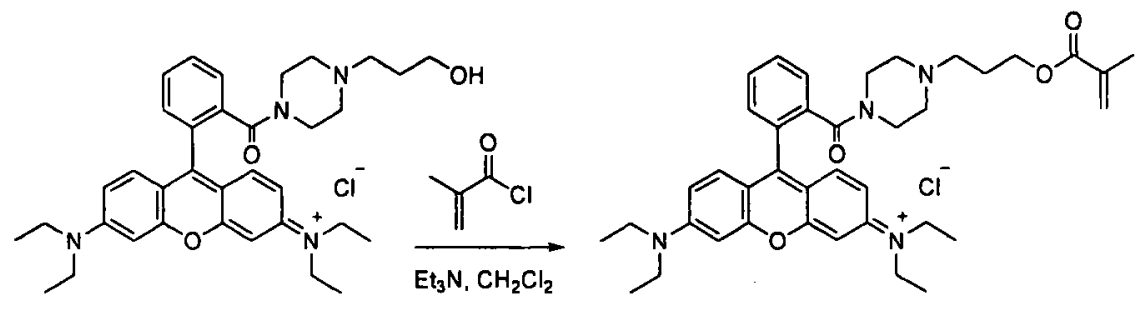

Scheme 1. Synthesis of the rhodamine B methacrylate monomer.

The method proposed by Francis et al. (19) allowed the preparation of a rhodamine B-based alcohol which was subsequently transformed into the corresponding methacrylate monomer by reaction with methacryloyl chloride. This synthetic route was chosen for three main beneficial reasons: (i) contrary to secondary amides of rhodamine, tertiary amides to not undergo intramolecular cyclization which results in a loss of fluorescence; (ii) this fluorescent compound is highly soluble in aqueous solutions and retains its fluorescence emission under a broad range of $\mathrm{pH}$ and (iii) it enlarges our range of fluorescent probes.

The resulting rhodamine $\mathrm{B}$ methacrylate monomer was obtained with high purity and gave a $\lambda_{\text {ex. }}=566 \mathrm{~nm}$ with $\lambda_{\text {em. }}=587 \mathrm{~nm}$ in $10 \mathrm{mM}$ PBS buffer $(\mathrm{pH}$ 
7.1) (Figure 1), leading to a Stokes shift of $21 \mathrm{~nm}$ in agreement with rhodamine B-tertiary amide spectral properties (19).

\section{BSA fluorescent bioconjugates}

Synthesis and characterization of the BSA-macroinitiator

Bovine Serum Albumin (BSA) is a $66 \mathrm{kDa}$ commercially available protein which was been selected as a model protein. The synthetic route for the synthesis of fluorescent bioconjugates based on BSA is represented in Scheme 2. The synthesis of the BSA-macroinitiator utilized the free cysteine residue (Cys-34) as a reactive functional group towards the maleimide initiator. It is known that only approximately $40-60 \%$ of free cysteine residues are available for protein modification in native BSA (20) and the number of thiols at the protein surface can be increased by appropriate reduction of disulfide bridges, although the latter approach mainly led to statistical multisite conjugation (13). In the present work we chose to prepare a BSA-monoinitiator using native BSA as the starting material, with unreacted non-thiol-containing BSA being the only observed byproduct.

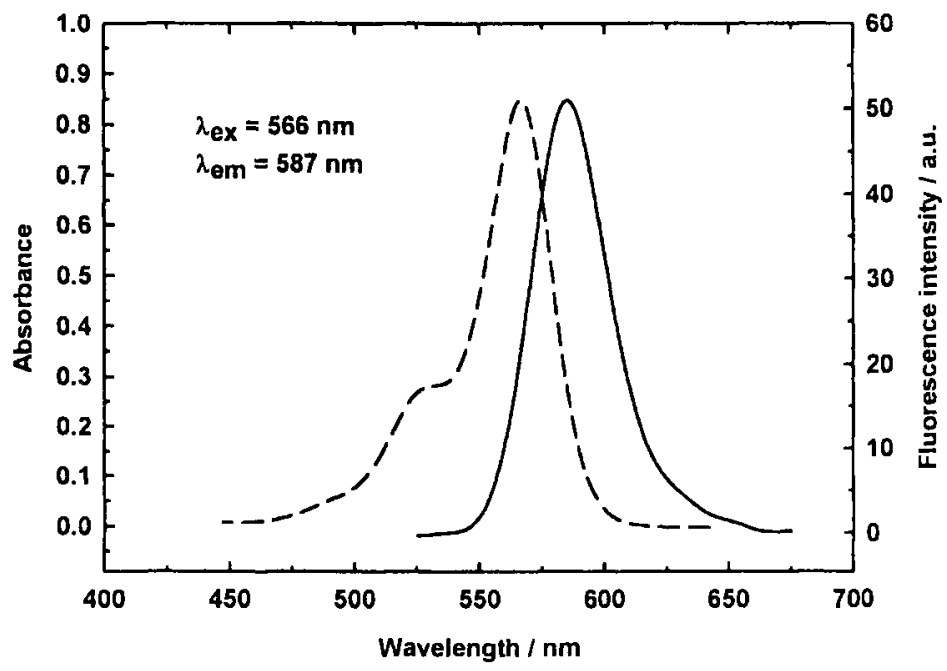

Figure 1. Absorption (dashed line) and emission (solid line) spectra of the rhodamine B methacrylate monomer in $10 \mathrm{mM}$ PBS buffer ( $p H 7.1$ ). 

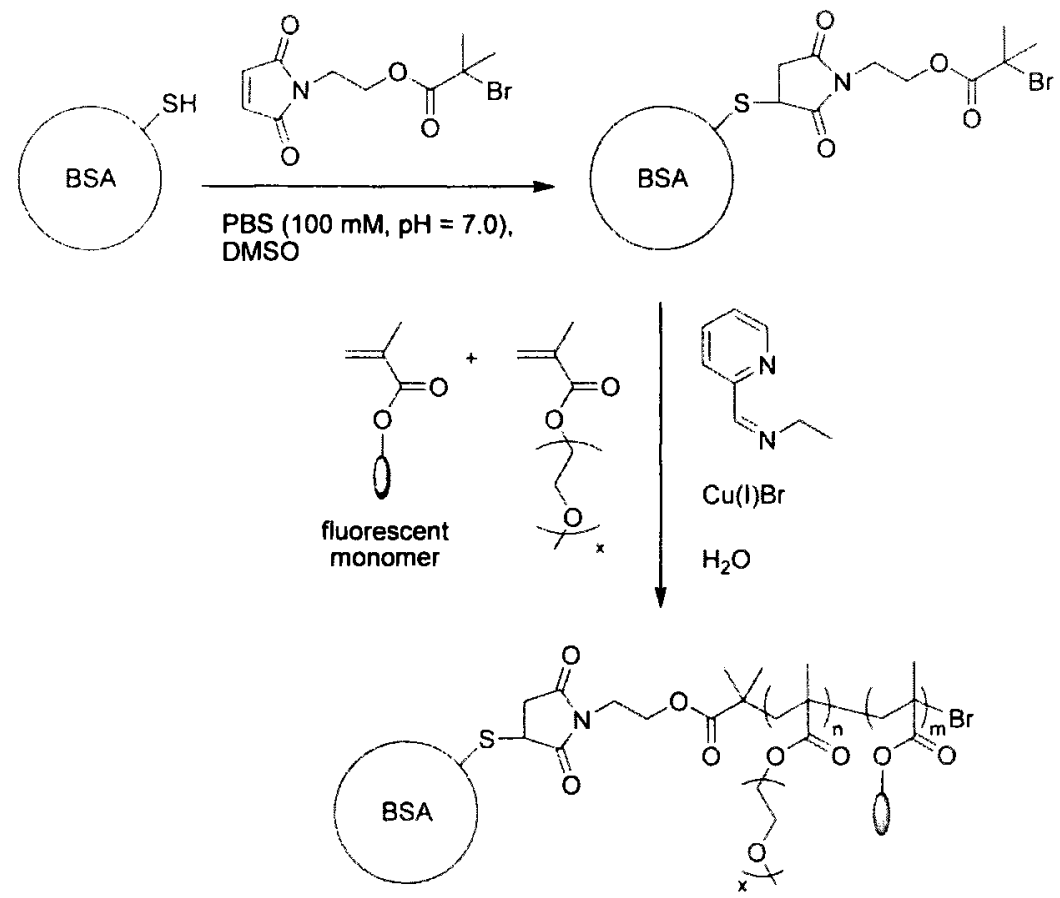

Scheme 2. Synthesis of the BSA fluorescent bioconjugates.

Each step of the synthesis of the bioconjugate was monitored by Sodium Dodecyl Sulfate Polyacrylamide Gel Electrophoresis (SDS-PAGE). Compared to the native BSA (band at $66 \mathrm{kDa}$ ), the BSA-macroinitiator exhibited two visible bands: The most significant band was slightly higher than $66 \mathrm{kDa}$ and the second was spread out from $200 \mathrm{kDa}$ to higher molecular weight (Figure 2). The presence of the second band can be ascribed to the aggregation phenomenon in which BSA oligomerizes via intermolecular thiol-disulfide interchange reaction (21). However, the relative intensities of the two bands indicate that only a minor fraction of BSA starting material undergoes oligomerization. SDS-PAGE analysis also revealed that traces of high molecular weight oligomers were already present in the commercially available native BSA.

BSA oligomerization has been reported to induce some protein conformational changes, especially a decrease of the $\alpha$-helix accompanied by an increase of $\beta$-sheet substructures (2l). Circular dichroism (CD) analysis of native BSA and BSA-macroinitiator revealed that the $\alpha$-helix content decreased from 54 to $43 \%$ whereas the $\beta$-sheet content increased from 1 to $8 \%$ by passing from the former to the latter. This may be ascribed to the presence of oliggmeric impurities in the BSA-macroinitiator, although a conformational change due to the attachment of the initiator moiety to the BSA cannot be ruled out. 


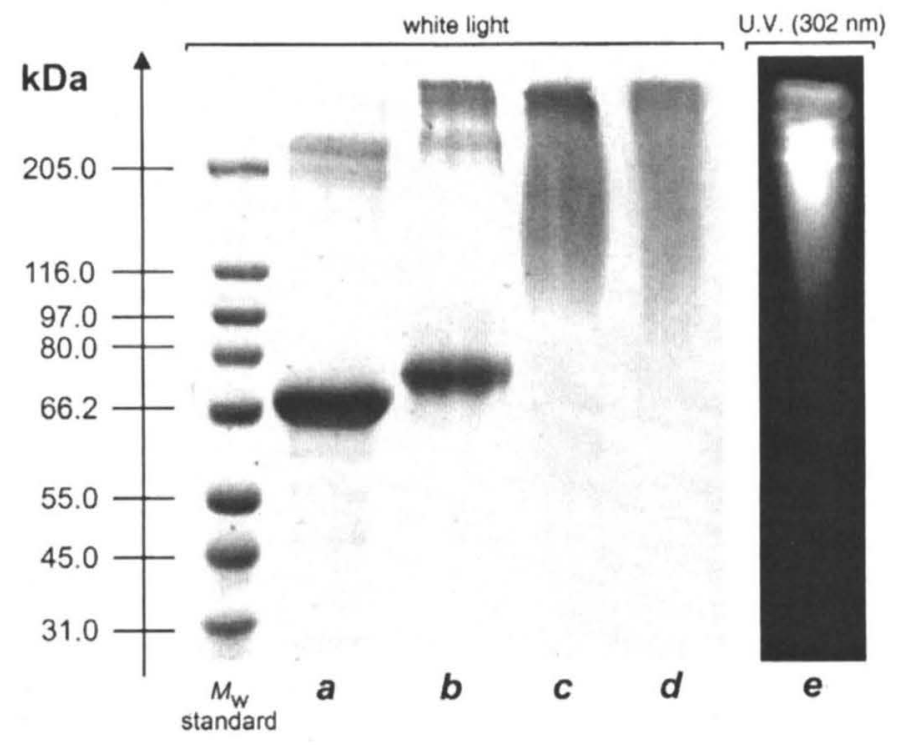

Figure 2. SDS-PAGE of (a) native BSA, (b) BSA-macroinitiator, (c) BSApoly(DMAEMA-co-rhodamine B methacrylate), (d) BSA-poly(PEGMA ${ }_{475}-c o-$ rhodamine B methacrylate) and (e) BSA-poly(PEGMA 475 -co-rhodamine $B$ methacrylate) under U.V. light at $\lambda=302 \mathrm{~nm}$.

RP-HPLC using a $\mathrm{C}_{18}$ column (Figure 3 ) showed separation between native BSA (retention time $=17.0 \mathrm{~min}$ ) and BSA-macroinitiator (retention time $=19.5$ $\mathrm{min}$ ), The BSA-macroinitiator also presented small peak observed at $14.6 \mathrm{~min}$, ascribed to the presence of BSA oligomers.

Synthesis and spectral properties of the BSA fluorescent bioconjugates

The isolated BSA-macroinitiator was used to initiate the polymerization of PEGMA $_{475}$ and DMAEMA using both hostasol and rhodamine B methacrylate fluorescent comonomers. After $48 \mathrm{~h}$ of polymerization at ambient temperature, the bioconjugates were purified and isolated by dialysis and lyophilization in order to remove unreacted monomers, especially remaining fluorescent monomers. The bioconjugation reaction was assessed by SDS-PAGE (Figure 2) where a shift from the BSA-macroinitiator to higher molecular weight was observed for both PEGMA 475 and DMAEMA polymerizations. Due to the incorporated rhodamine $\mathrm{B}$ fluorescent probe, the bioconjugate can also be detected by U.V. excitation $(\lambda=302 \mathrm{~nm})$. 

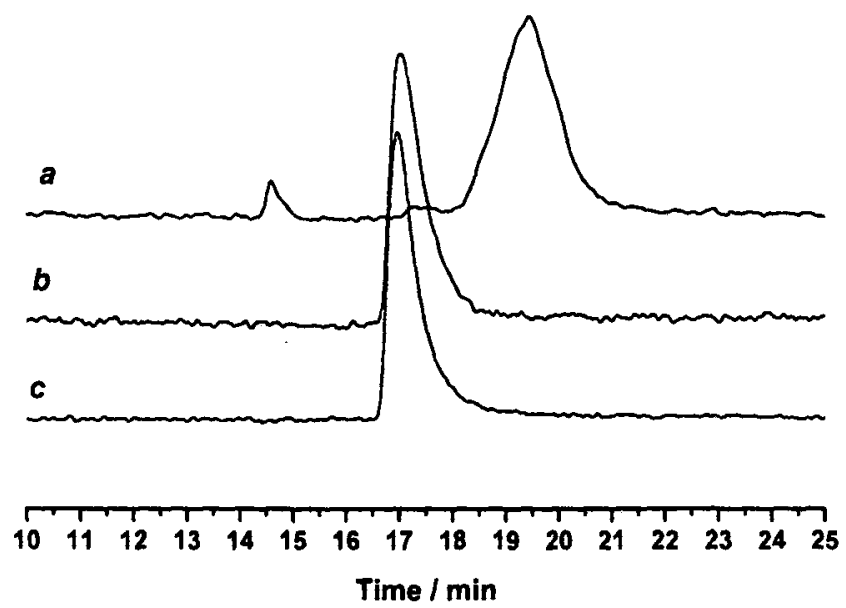

Figure 3. RP-HPLC of native (a) BSA, (b) control experiment and (c) BSAmacroinitiator. Control experiment: $B S A$ in $P B S(100 \mathrm{mM}, \mathrm{pH}=7.0)$ with $D M S O$, stirred overnight at ambient temperature.

As expected, solutions of the bioconjugates in phosphate buffer $(10 \mathrm{mM}, \mathrm{pH}$ $=7.1$ ) exhibited a strong fluorescence in agreement with the respective excitation/emission spectra of the rhodamine $\mathrm{B}$ and hostasol methacrylate fluorescent monomers (Figure 4).

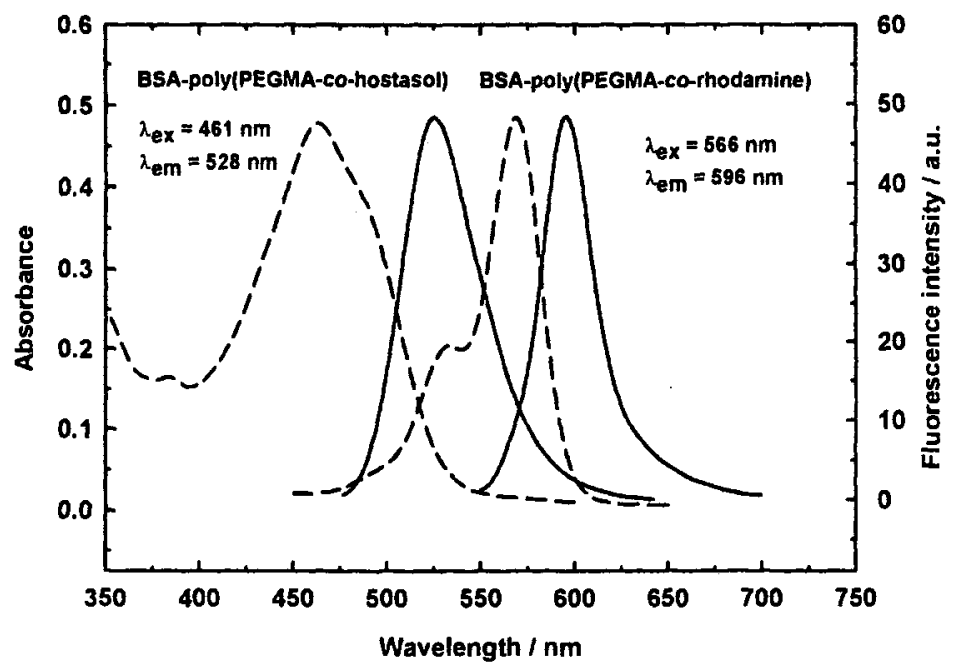

Figure 4. Absorption (dashed line) and emission.(solid line) spectra of $B S A$ poly(PEGMA ${ }_{775^{-}}$-co-hostasol methacrylate) and BSA-poly(PEGMA ${ }_{475^{-}}$-corhodamine $B$ methacrvlate) flunrescent hinconiugates. 
With both copolymerized fluorescent monomers the obtained fluorescent bioconjugates could be detected by SEC-HPLC with fluorescence detection (at appropriate $\lambda_{\mathrm{ex}}$ and $\lambda_{\mathrm{em}}$. for each fluorescent monomer) (Figure 5). This confirmed that the fluorescent probes had been incorporated in situ into the synthetic polymer-protein conjugate during the polymerization. In addition, SEC-FL-HPLC analysis revealed the absence of unreacted fluorescent monomers in the bioconjugate samples.

\section{Lysozyme fluorescent bioconjugate}

\section{Synthesis of the lysozyme-macroinitiator}

In order to demonstrate the flexibility of this approach, a similar synthetic route was investigated with lysozyme. The strategy for conducting bioconjugation was to target the free amine groups for multi-site attachment with the $N$-succinimidyl 2-bromo-2-methylpropionate (Scheme 3).

RP-HPLC analysis showed an almost complete disappearance of the native lysozyme peak along with the appearance of the lysozyme-macroinitiator peak. The relative broadness of the latter may indicate the presence of a statistical macroinitiators mixture in which different number of bromoisobutyrate initiator moieties are bound to the lysozyme core. The SDS-PAGE did not show any noticeable difference between the native lysozyme and the lysozymemacroinitiator (Figure 6); in particular no formation of side products at higher molecular weight was observed.

Synthesis and characterization of the lysozyme fluorescent bioconjugate

The lysozyme-macroinitiator was used for the polymerization of PEGMA 475 in aqueous solution under living radical polymerization conditions with the rhodamine $\mathrm{B}$ monomer as a fluorescent probe. After polymerization, the lysozyme-poly(PEGMA ${ }_{475}$-co-rhodamine $\mathrm{B}$ methacrylate) conjugate was purified and isolated by dialysis and lyophilization in order to remove unreacted monomers. The spectral properties of the fluorescent lysozyme bioconjugate were determined and, as expected, absorption and emission spectra of the bioconjugate are in very good agreement with those of pure rhodamine $B$ monomer (Figure 7).

The lysozyme-poly(PEGMA 475 -co-rhodamine $\mathrm{B}$ methacrylate) conjugate was observed by SEC-HPLC equipped with fluorescence detection $\left(\lambda_{\text {ex. }}=566\right.$ $\mathrm{nm}$ and $\lambda_{\mathrm{em}}=596 \mathrm{~nm}$ ), which confirmed the incorporation of the fluorescent probe in situ during the polymerization reaction of PEGMA $_{475}$ initiated py the 

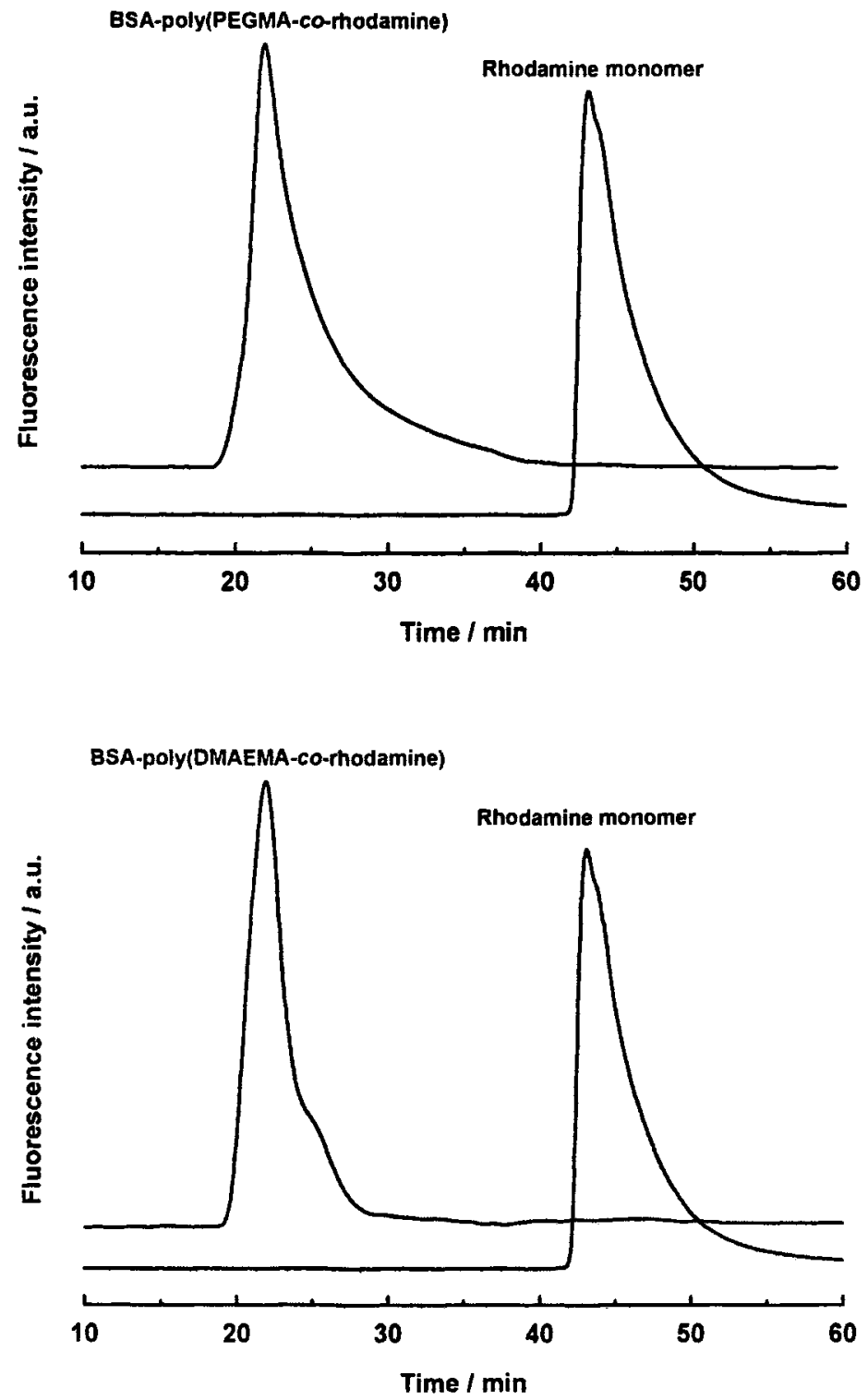

Figure 5. Top: SEC-FL-HPLC of BSA-poly(PEGMA ${ }_{475-c o-r h o d a m i n e ~} B$ methacrylate) bioconjugate and of the rhodamine $B$ methacrylate monomer.

Bottom: SEC-FL-HPLC of the BSA-poly(DMAEMA-co-rhodamine B methacrylate) bioconjugate and of the rhodamine $B$ monomer, $\lambda_{\text {ex. }}=566 \mathrm{~nm}$ and $\lambda_{\text {em. }}=596 \mathrm{~nm}$. 


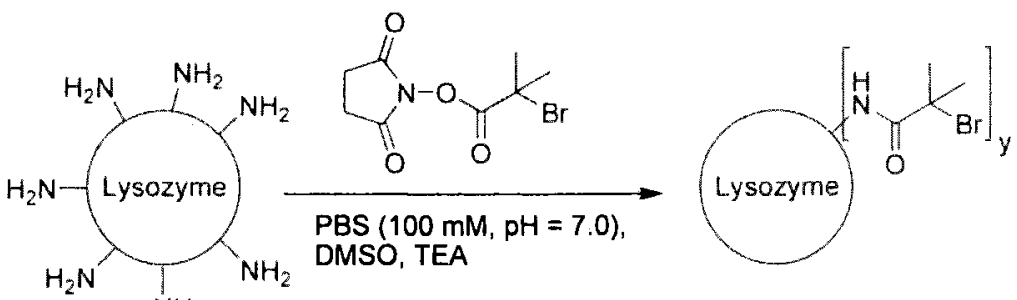

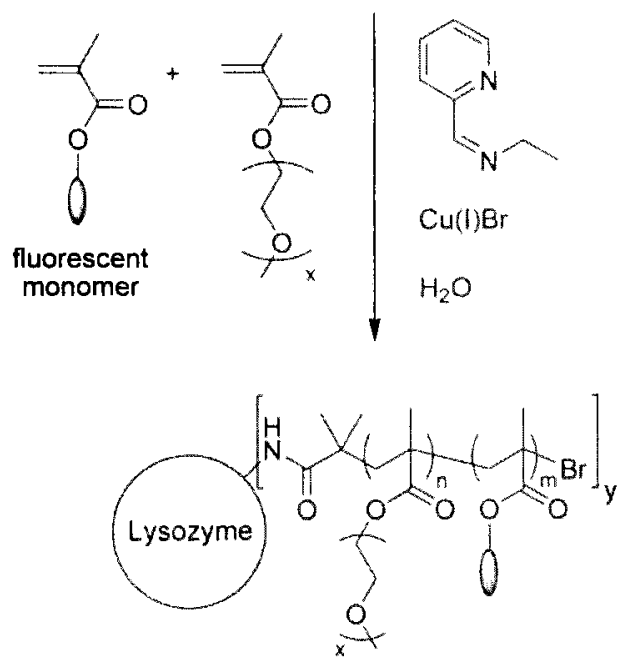

Scheme 3. Synthesis of the lysozyme fluorescent bioconjugate by living radical polymerization.

lysozyme-macroinitiator (Figure 8). A broad peak for the lysozyme bioconjugate was observed, probably due to the use of lysozyme-macroinitiators featuring a different number of initiating centers, which induced a broader molar mass distribution in the resulting biohybrid material, a behaviour that is commonly observed in living radical polymerization using multifunctional initiators.

\section{Conclusions}

Bovine serum albumin and lysozyme have been transformed into macroinitiators for the synthesis of fluorescent bioconjugates exploiting living radical polymerization. For this purpose, we have designed and synthesized a new fluorescent methacrylate monomer derived from rhodamine $B$. The bioconjugation reactions were assessed and these bioconjugates were detected by HPLC with fluorescent detection, giving rise to a new strategy for in $_{4}$ situ 


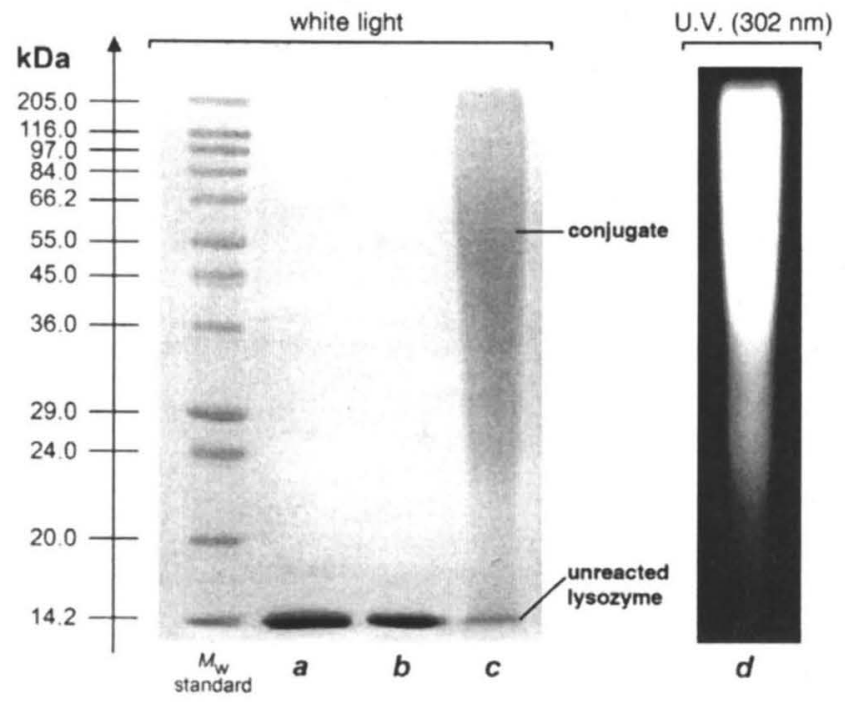

Figure 6. SDS-PAGE of (a) native lysozyme, (b) lysozyme-macroinitiator, (c) lysozyme-poly(PEGMA 475 -co-rhodamine B methacrylate) and (d) lysozymepoly(PEGMA ${ }_{475}$-co-rhodamine B methacrylate) under U.V. light at $302 \mathrm{~nm}$.

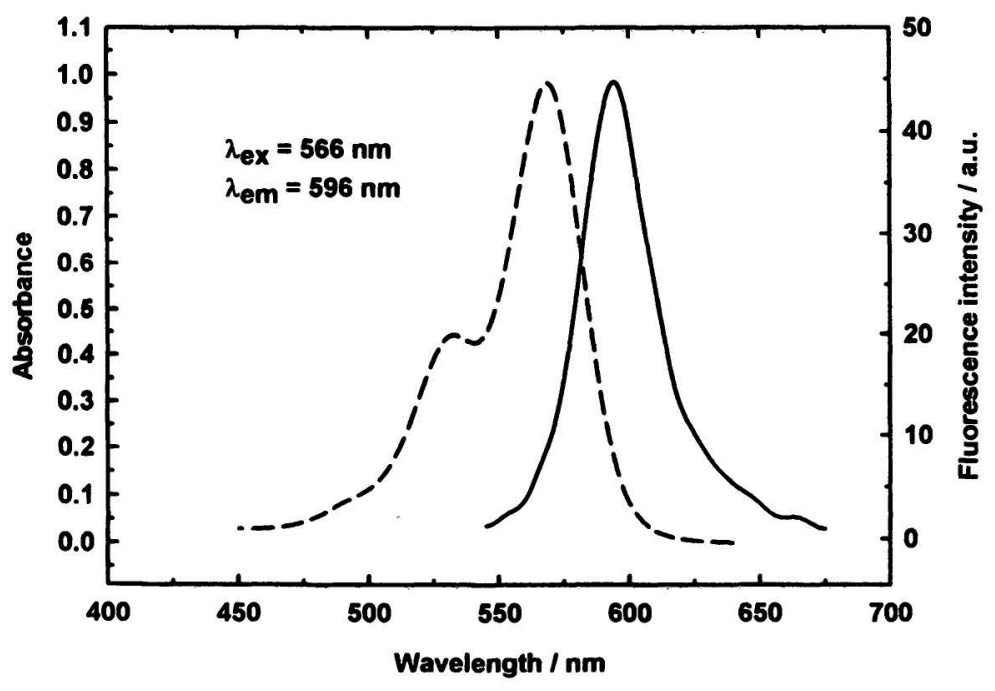

Figure 7. Absorption (dashed line) and emission (solid line) spectra of the lysozyme-poly(PEGMA ${ }_{475}$-co-rhodamine B methacrylate) fluorescint bioconjugate. 


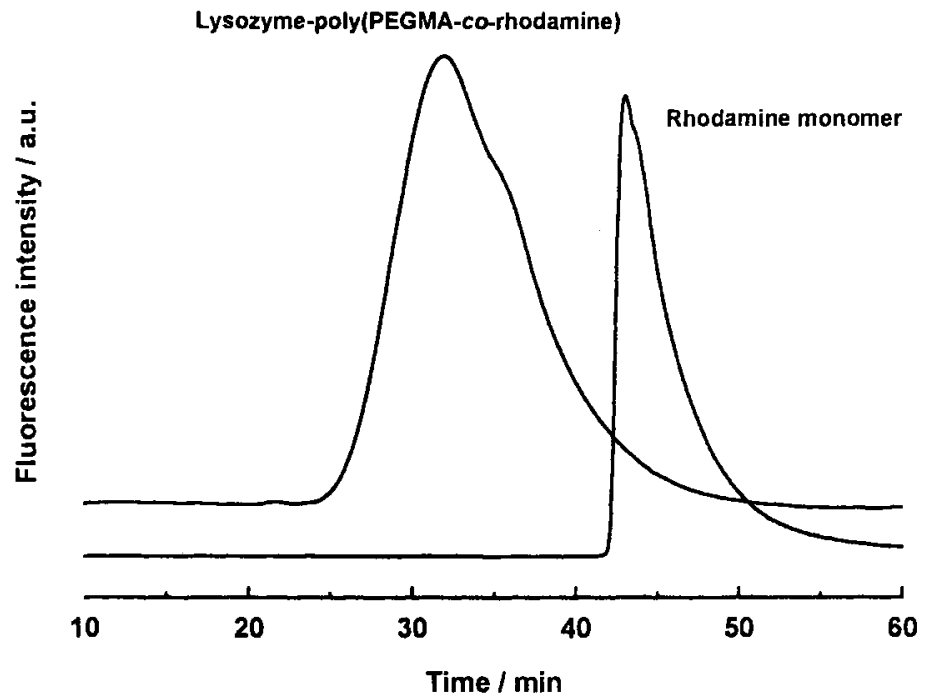

Figure 8. SEC-FL-HPLC of lysozyme-poly(PEGMA ${ }_{475}$-co-rhodamine $B$ methacrylate) bioconjugate and of the rhodamine $B$ methacrylate monomer $\left(\lambda_{e x}\right.$. $=566 \mathrm{~nm}$ and $\lambda_{\text {em }}=596 \mathrm{~nm}$ ).

observation of delivered compounds. ${ }^{22}$ This strategy is quite generic and applicable to a wide range of proteins and peptides.

\section{References}

1. Abuchowski, A.; Van Es, T.; Palczuk, N. C.; Davis, F. F. J. Biol. Chem. $1977,252,3578$.

2. Harris, J. M.; Chess, R. B. Nat. Rev. Drug Discov. 2003, 2, 214.

3. Veronese, F. M.; Harris, J. M. Adv. Drug Deliver. Rev. 2002, 54, 453.

4. Roberts, M. J.; Bentley, M. D.; Harris, J. M. Adv. Drug Deliver. Rev. 2002, $54,459$.

5. Veronese, F. M. Biomaterials 2001, 22, 405.

6. Matyjaszewski, K.; Xia, J. Chem. Rev. 2001, 101, 2921.

7. Kamigaito, M.; Ando, T.; Sawamoto, M. Chem. Rev. 2001, 101, 3689.

8. Hawker, C. J.; Bosman, A. W.; Harth, E. Chem. Rev. 2001, I0l, 3661.

9. Perrier, S.; Takolpuckdee, P. J. Polym. Sci., Part A: Polym. Chem. 2005, 43, 5347.

10. Tao, L.; Mantovani, G.; Lecolley, F.; Haddleton, D. M. J. Am. Chem ${ }_{46} S o c$. 2004, 126, 13220. 
11. Lecolley, F.; Tao, L.; Mantovani, G.; Durkin, I.; Lautru, S.; Haddleton, D. M. Chem. Commun. 2004, 2026.

12. Mantovani, G.; Lecolley, F.; Tao, L.; Haddleton, D. M.; Clerx, J.; Cornelissen, J. J.; Velonia, K. J. Am. Chem. Soc. 2005, 127, 2966.

13. Heredia, K. L.; Bontempo, D.; Ly, T.; Byers, J. T.; Halstenberg, S.; Maynard, H. D. J. Am. Chem. Soc. 2005, 127, 16955.

14. Bhalchandra, S. L.; Hironobu, M.; Matyjaszewski, K.; Russell, A. J. Biomacromolecules 2005, 6, 3380 .

15. Haddleton, D. M.; Crossman, M. C.; Dana, B. H.; Duncalf, D. J.; Heming, A. M.; Kukulj, D.; Shooter, A. J. Macromolecules 1999, 32, 2110.

16. Limer, A. J.; Rullay, A. K.; San Miguel, V.; Peinado, C.; Kelly, S.; Fitzpatrick, E.; Carrington, S. D.; Brayden, D.; Haddleton, D. M. React. Funct. Polym. 2006, 66, 51.

17. Laemmli, U. K. Nature 1970, 227, 680.

18. Johnson, W. C. Proteins Struct. Funct. Genet. 1999, 35, 307.

19. Nguyen, T.; Francis, M. B. Org. Lett. 2003, 5, 3245.

20. Janatova, J. F.; Fuller, J. K.; Hunter, M. J. J. Biol. Chem. 1968, 243, 3612.

21. Maruyama, T.; Katoh, S.; Nakajima, N.; Nabetani, H. Biotechnol. Bioeng., 2001, 75, 233.

22. Nicolas, J.; San Miguel, V.; Mantovani, G.; Haddleton, D. M. Chem. Commun. 2006, 4697. 